\title{
Determinants of Reporting Rates for HIV Test-kits; A Case of Meru County
}

\author{
Paul Gathii \\ Department of Health Systems \\ Management \\ Kenya Methodist University
}

\author{
Caroline Kawila, PhD \\ Department of Health Systems \\ Management \\ Kenya Methodist University
}

\author{
Lillian Muiruri \\ Department of Health Systems \\ Management \\ Kenya Methodist University
}

\begin{abstract}
Background: Many health organizations including Ministry of Health through Kenya Medical Supplies Authority have adopted reporting rates as a measure for improving health service delivery in terms of ensuring the availability of health commodities and product supply. Uninterrupted health commodity supply is determined by ensuring commodity reports are uploaded into District Health Information System 2 platform which is a national system for consolidating consumption data. It is this data that the national allocation committee uses to quantify HIV test kits required by facilities on quarterly basis.

Methods: The study embraced quantitative research design where quantitative approach was used. The study target population was 260 Healthcare workers in Meru County to assess the role or the factors that affect the reporting rates of HIV test kits. The study used purposive sampling technique to sample the respondent's i.e. Health care workers who are responsible for consolidating facility level HIV test kits reports in Meru County Therefore the sample size was 260 health care workers. The study used semi structured questionnaires and data extraction sheet to collect the data. Majority were familiar with the recommended data reporting tools (MOH 643).
\end{abstract}

Results: Majority 153(, 61.2\%) were familiar with the recommended reporting tools $(\mathrm{MOH} 643)(x 2=101.76$, $\mathrm{p}<0.05)$ slightly more than half of the Healthcare workers were regularly trained in the recommended data reporting tools (MOH 643 tool) 145, (58.0\%) $(x 2=6.4, \quad \mathrm{p}<0.05)$. Approximately 101(40.4\%) that recommended data reporting tools( $\mathrm{MOH} 643)$ is adequate in capturing the consumption data of the HIV test kits $(x 2=77.67, \mathrm{p}<0.05)$. Most respondents indicated that the trainings were not useful compared to a third indicated that the trainings were useful.. The respondents agreed to the statement that they were aware of HIV test kits policies that are in place and the agreed that the policies were helpful at their work. The respondents agreed that they had a supervisor whom they report to in the course of their work and that their supervisor was not always available for consultation. There was strong positive relationship that was significant $(\mathrm{p}<0.05)$ between reporting rates and availability of the reporting tools $(\mathrm{rho}=.693, \mathrm{p}<0.05)$ while a strong positive relationship existed between reporting rates and availability of Standard operating Procedure $(\mathrm{rho}=.814, \mathrm{p}<0.05)$ and a strong relationship between the reporting rates and human capacity $(\mathrm{rho}=.896, \mathrm{p}=054)$ and support supervision (rho=-.407, $\mathrm{p}=.053$ ).

Conclusion: presence of enough staffs, availability of Standard Operating Procedure, supportive supervision all affects reporting rates for HIV testing kits. The coefficient of determination obtained from the model was .663 and this indicated that the regression model explained only $66.3 \%$ of the factors that affected the reporting rates on consumption data of HIV test kits in the county.

\section{Keywords}

Reporting Rates, Human Capacity, Standard Operating Procedure, Support Supervision, reporting tools, HIV test kits

\section{INTRODUCTION}

Commodity reports plays a key role in assisting the national allocation team to quantify and project HIV test kits based on workload on quarterly basis. This helps to reduce on either under stocking or overstocking of HIV test kits across the country. As a standard, facilities are supposed to report $100 \%$ on HIV test kits on monthly basis to give accurate estimate of HIV test kits needs at the end of the quarter projected based on average month consumption (AMC). This follows the national guidance on commodity management by Management Science for Health commodity report, 2016 which clearly stipulate the recommend standard to be followed from distribution of HIV test kits by KEMSA to reporting of consumption data through DHIS.

Consumption data on HIV test kits is usually reported using Ministry of Health(MOH) 643 which is a standardized reporting tool . This is usually done every $5^{\text {th }}$ day of the following month by Health care workers. Filled MOH 643 tool is then shared with respective Sub county Medical Laboratory Coordinator (SCMLC) at the sub county level. The commodity data captured is then uploaded into District Health Information System (DHIS) which is a National reporting system that is accessible to everyone including partners, National allocation team and other key stakeholders.

According to The National Guidelines for HIV Commodity Information Systems, 2016, DHIS provides functionality to validate data during data entry, after entry, analysis of datasets and through data triangulation in order to improve data quality. This is done through the creation of validation rules against data elements. After a validation rule has been executed, it will display one of two outcomes - successful validation or detection of violation

\section{EMPIRICAL REVIEW}

According to Martin and Simmons (2017), having the recommended reporting tools ensure the availability of quality information which is crucial for quick and rational health decisions which is relevant in health services delivery. Lack of standardized data reporting tools, notwithstanding, can cause data over-burden, leaving leaders covered under a mass of unessential, deficient, and conflicting information. Some healthcare and medical care facilities figure out how to furnish their chiefs with exact, significant information in a simple to- 
get a handle on format by standardizing tools used for data collection

According to the National guidelines for quantification of HIV commodities (2016), Commodity reporting tools should be standardized, harmonized, printed and distributed targeting sites offering Health services across the country. This is then followed by sensitization meetings targeting end users who are health care workers responsible for reporting consumption data on monthly basis. Harmonization of training curriculum on commodity reporting tools should be done and Trainers of Trainees (TOT) identified who will then be used to cascade trainings to the various regions across the country. As public governments work with their partners to excuse numerous upward stock frameworks, a significant advance is to normalize information assortment apparatuses and detailing frameworks and designs. Information frameworks for benefactor financed vertical projects are normally intended to meet the particular detailing prerequisites of the subsidizing source. The test in excusing various equal ware the board data frameworks lies in agreeing on a base arrangement of information that the framework will give an account of to try not to over-burden it. Moreover, achievement will rely upon planning a data framework that can follow items and report use and stock information by financing source and program.

Management Sciences for Health (2018), Reporting tools allow data specialists and policy makers to extract also, present information in outlines, tables, and different representations so clients can discover valuable data. It can likewise permit to fabricate paginated reports ideal for printing. A detailing apparatus is normally an application inside a DHIS site, for example, MOH 643 in wellbeing administrations. Reports gave can change in their intuitiveness. In wellbeing, static reports can't be changed by the end clients (DHS) while intuitive reports permit Sub County Medical Laboratory Coordinators (SCMLCs) to explore the reports through different orders and perception components. Intelligent reports permit boring down through different levels of the information at the snap of a catch. They likewise permit to explore, sort, channel and view the information for your particular necessities

Monica (2016) pointed that commodity reporting tools should be simple, easy to use and help to maintain history of data on consumption such those of HIV test kits and further; these reporting tools should further assist improve quality of data and in business applications to generate reports like annual and quarterly comparisons of sales and salary etc. . Reporting tools should ideally be the one that can be updated and reviewed to meet the changing demands. The changes should as well reflect in the National Dashboards which should be flexible to accommodate the changing demands/trend.

Sibanda et al (2018) argued that, availability of recommended reporting tools for HIV Test kits provided enough data for the number of HIV testing services offered worldwide. According to WHO [2019], between 2015 and 2019 more than 800 million people received HIV testing services in 122 low- and middle income countries and this was achieved by ensuring proper HIV test units reporting tools were set up to create the important information on HIV testing take-up. Worldwide AIDS Update [2018] brought up that in 2017, it was assessed that, universally, $75 \%$ of individuals with HIV knew about their HIV positive status, an expansion from $67 \%$ in 2015 (Global AIDS Update 2018).
Human resources for health $(\mathrm{HRH})$ have long been recognized as the cornerstone of health sector to produce, deliver and manage services. Training of Health care workers especially medical laboratory Technologists involved in testing patients on HIV test involves ID of the requirements for preparing and improvement and choosing techniques and projects reasonable for these necessities, plan how to carry out them lastly assessing their result brings about giving and signing in utilization information (McCourt and Eldridge 2003). Visitor (1987) contends that strategies are important to guarantee that representative presentation is assessed, which thus guarantees that the fitting preparing and improvement occur.

Chuang [2013] completed an investigation and noticed that training was best in creation of and holding great HR accountable for increasing their employees competent through regular trainings and seminars (Chuang, 2013). Critically, it has been noticed that training is a vital component of the heaps of works on emerging from research on superior and conducive work environment (Chapagain, 2009) in healthcare settings. Recent research likewise demonstrates a causal connection between high responsibility works on (counting preparing) and upgrades in a detailing rates in reporting health commodities (McClean and Collins, 2011, Kwon, Bae, and Lawler, 2010). (Burma, 2014) inferred that training is a factor that upgrades worker responsibility and commitment and amplifies employee potential.

Organizational training activities are perceived as having the option to become wellsprings of upper hand through their effect on workers' efficiency (Hutchings, Zhu, Cooper, Zhang, and Shao, 2009). As the requirement for current and future successful managers increments in a wide range of medical services, preparing projects and $\mathrm{CME}$ and configuration apparatuses for the assessment interaction become more significant (Stredwick, 2014)

Policy and guidelines are necessity in the provision of quality health services. Standard Operating Procedures refer to the written documents that describe step-by-step instructions on how to perform various operations a testing site. All health faculties should keep inventory of all supplies and materials used for testing to ensure interruptions to testing do not occur in regard of Standard Operating Procedures (SOPs) on the reporting rates of HIV test kits utilization

According to FHI (2019) many countries are still trying or developing necessary strategic plans necessary for the implementation of Policy and guidelines that are needed for scaling up utilization and use/consumption. According to WHO (2020), they pointed that national policies and regulations are prerequisite for promotion, support implementation of sound practices for HIVST. Further, national guidelines are a must pre-requisite for the development of regulations, including the capacity to procure and import products.

Agarwal [2020] carried out a study on Standard operating procedures for HIV \& Syphilis Screening of pregnant women. $\mathrm{He}$ found out that presence of SOPs that dictate on the procurement of HIV test kits and other health commodities were paramount in assessing when and which facilities were running on which health commodities

According to Clark and Hoghins [2019] in the study that focused on the monitoring evaluation and reporting Indicator guide, presence of SOPs that mandated and regulated all 
logistical activities are crucial in determining stock outs and prioritizing all high-risk areas.

Supportive supervision is a way to deal with supervision that underscores tutoring, joint critical thinking, and two-way correspondence between the chief and those being administered. Djibouti, (2009) further demonstrated that the supportive supervision approach can be instrumental in reinforcing general wellbeing projects and general wellbeing results. With regards to a medical care framework, supportive supervision empowers and enables medical care workers to viably recognize and take care of issues, work with collaboration, give administration, and screen and work on their own presentation.

As per Asante and Roberts (2017), supportive supervision can be carried out or applied at different levels inside a general health system. For instance, for a given general wellbeing intercession, supportive supervision can serve to fortify assistance conveyance at the office level; general wellbeing program execution at the sub-public level; and program organization, observing, and assessment at the public level.

Bailey et al, (2020) carried out an efficient audit of supportive supervision as a $\mathrm{s}$ methodology to further develop essential healthcare administrations in Sub Saharan African. They tracked down that supportive supervision can expand work fulfillment and health specialist inspiration. Further, Supportive supervision then again is seen as an ideal decision for clinical consideration settings since it overturns customary thoughts of supervision and spotlights on assistance rather than assessment.

Karuga et al (2019) soughtto exhibit the impacts of a preparation intercession on the way to deal with and recurrence of supervision of CTC suppliers of health care. They found that managers had moved the supervision come closer from being controlling and regulatory to training, mentorship and critical thinking.

According to study done Dieleman, M., Gerretsen, B., \& van der Wilt, G. J. (2019) supervisors that provide supportive feedback play very important part of performance management processes and in the overall reporting rates in health commodities in healthcare facilities. Supportive superiors in an organization need to know how they are performing.

\section{METHODS}

The study adopted descriptive cross-sectional research design. The study target populations were Health Care Workers dealing with HIV test kits who are 260 in Meru County. This study utililised purposive sampling technique to sample the respondents i.e. Health Care workers who are responsible for reporting HIV test kits on monthly basis in Meru County, after which a census of all the 260 was undertaken. The study used a semi structured questionnaire

and data extraction sheet) see appendix II) to collect the data. The collected data was encoded and entered into computerized data analysis software, SPSS v25.The quantitative data in this research was analyzed by descriptive statistics using statistical package for social sciences SPSS (v25) Chi Square was used to assess the significance of individual factors

\section{RESULTS}

Table 1: Sociodemographic Characteristics

\begin{tabular}{|c|c|c|c|}
\hline Characteristic & & & $\%$ \\
\hline Gender & male & 179 & {$[72.0]$} \\
\hline & female & 71 & [28.0] \\
\hline age band & $\begin{array}{l}\text { between } \\
\text { vears }\end{array}$ & 55 & [22.0] \\
\hline & $\begin{array}{l}\text { between } \\
\text { years }\end{array}$ & 150 & [60.0] \\
\hline & $>45$ years & 45 & {$[18.0]$} \\
\hline highest education level & Diploma Level & 52 & [21.0] \\
\hline & Diploma & 97 & [39.0] \\
\hline & $\begin{array}{l}\text { Graduate/Degree } \\
\text { Level }\end{array}$ & 84 & [34.0] \\
\hline & Postgraduate Level & 17 & [6.] \\
\hline period in profession & $<$ than 1 year & 17 & {$[6.8]$} \\
\hline & between $1-5$ years & 86 & [34.0] \\
\hline & between $6-10$ years & 107 & [43.0] \\
\hline & $\begin{array}{l}\text { between } \\
\text { years }\end{array}$ & 38 & {$[15.0]$} \\
\hline & $>$ than 20 years & 2 & {$[.8]$} \\
\hline long have you worked in & $<1$ year & 4 & {$[2.0]$} \\
\hline МСH & between 1-5 years & 123 & [49.0] \\
\hline & between $6-10$ years & 110 & [44.0] \\
\hline & $>20$ years & 13 & {$[5.0]$} \\
\hline facility level are you & Hospital & 92 & [37.0] \\
\hline Irrently deployed in & Health Center & 122 & [48.8] \\
\hline & Dispensary & 36 & [14.4] \\
\hline
\end{tabular}

Majority of the respondents $150(60 \%)$ were aged between 3545 years and followed by those between 26-35 years $55,(22.0 \%)$. On their highest education level, majority had higher diploma level 97,(39\%) followed by those with graduate education $84,(33 \%)$ while those with either diploma level constituted $21 \%$. The study established that majority $107,(43 \%)$ had worked at their current station for between 610 years while those with experience of between $1-5$ years were $86(34.0 \%)$. On the period they had worked at the $\mathrm{MCH}$, the study established that $110(44.0 \%)$ had worked for between 6-10 years while those with who had worked for between 1-5 years were $123(49.0 \%)$ and most worked at health centers $122,(49 \%)$ while those who worked at the dispensary and hospitals were $36(14 \%)$ and $92(37 \%)$ respectively.

Availability of the Recommended Reporting Tools for HIV Test kits

Table 2: Availability of the Recommended Reporting Tools for HIV Test kits

\begin{tabular}{llllll}
\hline & & & Chi & Asymp. \\
& & $\mathrm{n}$ & $\%$ & Square & Sig. \\
\hline recommended Yes & 153 & {$[61.2]$} & 101.768 & .000 \\
data reporting No & 73 & {$[29.2]$} & & \\
tools (MOH 643 Somewhat & 24 & {$[9.6]$} & & \\
available & & & & &
\end{tabular}

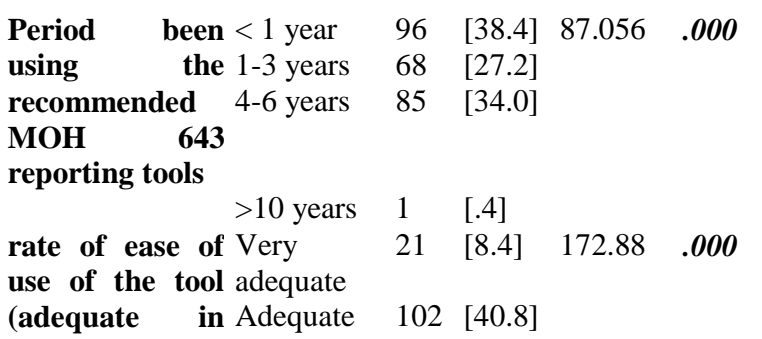




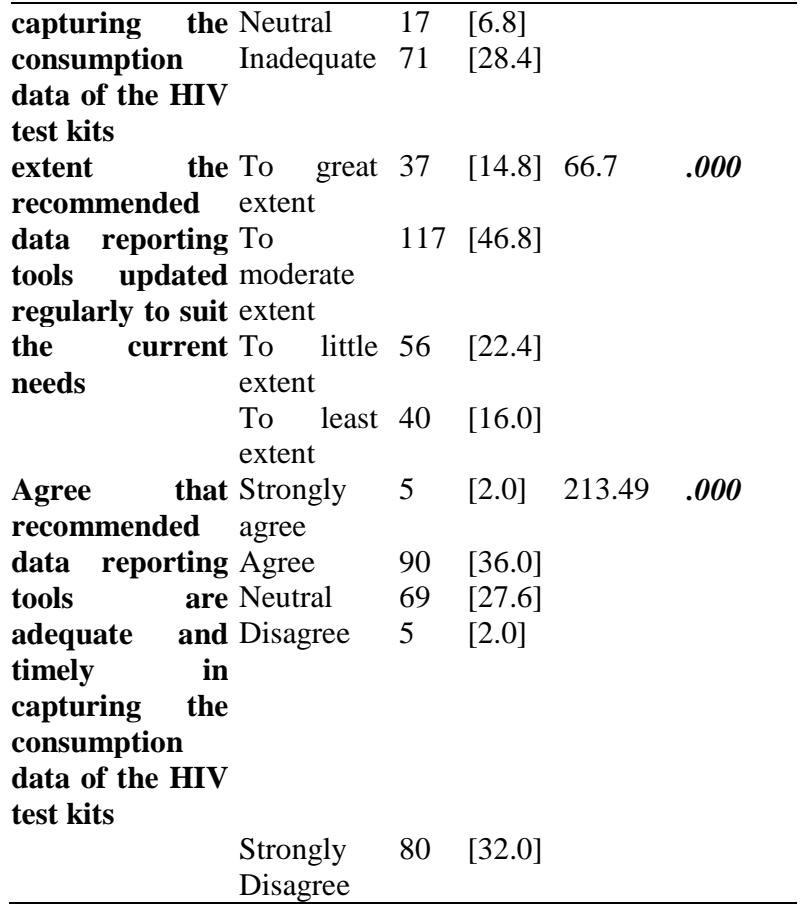

The study established that majority $153,(61.2 \%)$ had the recommended data reporting tools $(\mathrm{MOH} 643)(x 2=101.76$, $\mathrm{p}<0.05)$ and on the period they have been using the recommended $\mathrm{MOH} 643$ reporting tools, a third $(85,34 \%)$ indicated between $4-6$ years and $68(27.2 \%)$ indicated they have using $\mathrm{MOH} 643$ for between 1-3 years $(x 2=80.86$, $\mathrm{p}<0.05)$ while $98(38.7 \%)$ have been using the reporting tools(MOH 643) for less than one year and this indicated great gaps in reporting rates. Their ratings on the ease of use of commodity reporting tool (MOH 643) indicated that it was generally adequate $173,(40.8 \%)$ while $71(28.4 \%)$ said it was very inadequate and this indicated that the tool was inefficient and ineffective enough $(x 2=172.88, \mathrm{p}<0.05)$ and this might affect reporting rates.

Majority 117,( 46.8\%) were neutral that reporting tools were updated regularly to suit the current needs $(x 2=142.00$, $\mathrm{p}<0.05$. Commodity reporting tools are usually reviewed and updated when new HIV test kits are introduced and this is usually done by National Commodity Technical working group comprising of National HIV team and stakeholders drawn from all the counties. Upon approval by Nascop, the updated tools are then printed and distributed to the facilities across the country. The recommended data reporting tools are adequate in capturing the consumption data of the HIV test kits, $85(34.0 \%)$ disagreed compared to $95(38.0 \%)$ who agreed while $27.6 \%$ were neutral on the statement $(x 2=213.49$, $\mathrm{p}<0.05)$ and this showed commodity reporting tools $(\mathrm{MOH}$ 643) were not adequate enough. This disagree with Martin and Simmons (2017) recommendation that commodity reporting tools should be reviewed periodically or when need arises to accommodate new indicators that are key for policy formulation .Currently (2021).
Influence on Human capacity on HIV test kits reporting rates

Table 3: Influence on Human capacity on HIV test kits reporting rates

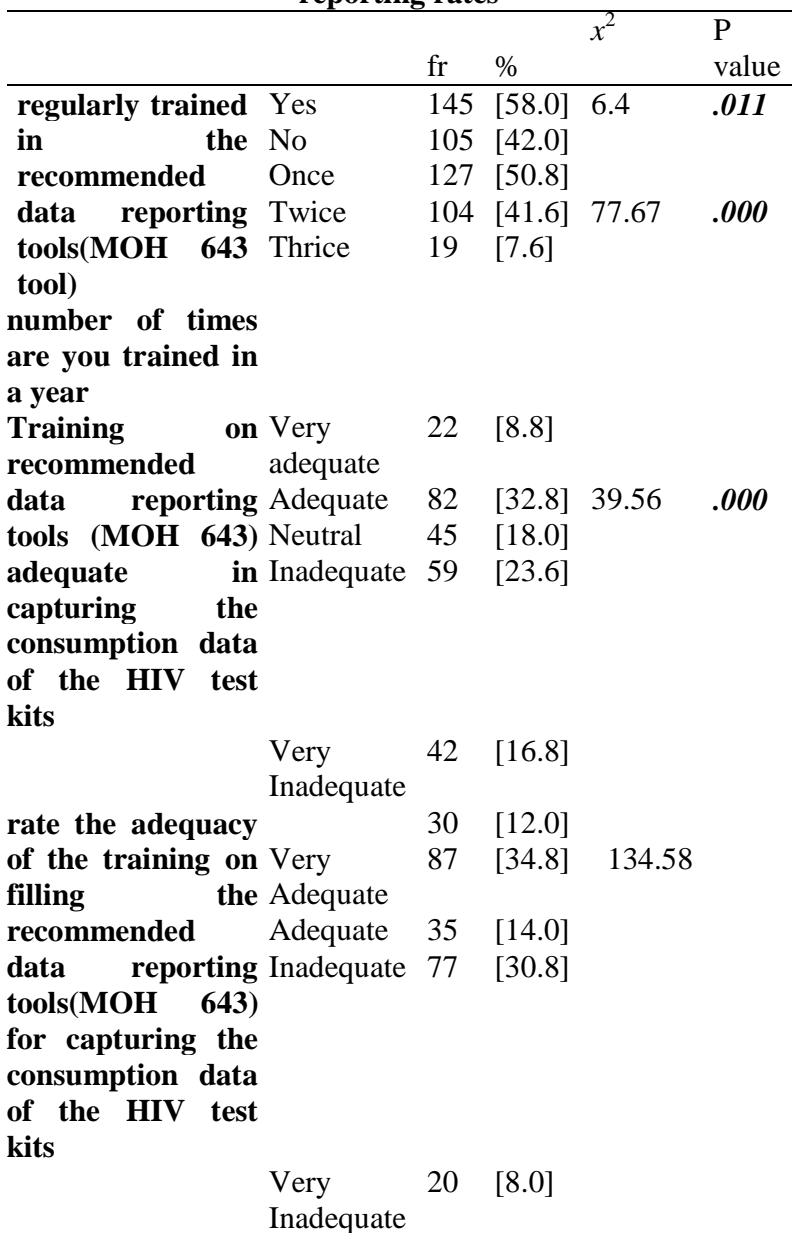

$\begin{array}{llllll}\text { extent did you find Extremely } & 14 & {[5.6]} & 89.800 & \mathbf{. 0 0 0}\end{array}$ the training useful useful

$\begin{array}{llll}\begin{array}{l}\text { Very } \\ \text { useful }\end{array} & 62 & {[24.8]} \\ \begin{array}{l}\text { Somewhat } \\ \text { useful }\end{array} & 86 & {[34.4]} \\ \begin{array}{l}\text { Not } \\ \text { useful }\end{array} & \text { so } & 73 & {[29.2]} \\ \begin{array}{l}\text { Not at all } \\ \text { useful }\end{array} & 15 & {[6.0]} \\ \end{array}$

agree that there Strongly $13 \quad[5.2] \quad 109.520 \quad .000$ are there enough agree staff in the facility Agree $\quad 90 \quad[36.0]$ to fill the Neutral 43 [17.2] consumption data Disagree 87 [34.8] of the HIV test

kits useful

$$
\text { Strongly } \quad 17 \quad[6.8]
$$

Disagree

Slightly more than half, $145(58 \%)$ of the Healthcare workers were regularly trained in the recommended data reporting tools (MOH 643 tool $)(145,58.0 \%)(x 2=6.4, \mathrm{p}<0.05)$ and this might explain the poor reporting rates and the number of trainings annually were only once 127,(50.8\%).. Approximately 101(40.4\%) recommended that data reporting tool $(\mathrm{MOH}$ 643) is adequate in capturing the consumption data of the HIV test kits $\left(x^{2}=77.67, \mathrm{p}<0.05\right)$. Majority of the respondents indicated that they were they were trained once 
$(127,50.8 \%)$ while $104(41.6 \%)$ indicted that they were trained twice and further query indicated that this once trainings affected the reporting rates due to inadequate competence. Trainings were not quite adequate in the capture of consumption data on HIV test kits as 101(40.4\%) cited inadequate compared to $104(41.6 \%)$ who indicated they were adequate $(x 2=39.56, \mathrm{p}<0.05)$.Inadequate trainings, $101(40 \%)$, in the capture of consumption data for HIV test kits can be as a results of perception among the health care workers.

the study noted that trainings were not useful $159,(63.6 \%)$ compared to $76(30.4 \%)$ indicated that the trainings were useful $(x 2=89.8, \mathrm{p}<0.05)$. majority of the respondents $104,(41.6 \%)$ disagreed that there were enough staffs in the facility to fill the consumption data of the HIV test kits useful compared to $103(41.2 \%)$ who agreed to the statement $(x 2=109.52, \mathrm{p}<0.05)$ and inadequate staff can lead to burnouts and responsibilities overload and this can affect the overall reporting rates. Human resource for Health as one of WHO building blocks plays a key roles as one of the drivers towards achieving quality service delivery.

Availability of Standard Operating Procedures and HIV test Kits Reporting Rates

Table 4: Availability of Standard Operating Procedure and HIV test Kits Reporting Rates

\begin{tabular}{|c|c|c|c|c|}
\hline & Mean & $\begin{array}{l}\text { Std. } \\
\text { Deviation }\end{array}$ & $\begin{array}{l}\text { Chi- } \\
\text { Square }\end{array}$ & $\begin{array}{l}\text { Asymp } \\
\text {. Sig. }\end{array}$ \\
\hline $\begin{array}{l}\text { I am aware } \\
\text { of HIV test } \\
\text { kits policies } \\
\text { that are in } \\
\text { place }\end{array}$ & $\begin{array}{l}3.884 \\
0\end{array}$ & 0.65134 & $\begin{array}{l}189.64 \\
8\end{array}$ & .000 \\
\hline $\begin{array}{l}\text { The policies } \\
\text { are helpful } \\
\text { in my work }\end{array}$ & $\begin{array}{l}3.888 \\
0\end{array}$ & 0.70814 & $\begin{array}{l}312.48 \\
0\end{array}$ & .000 \\
\hline $\begin{array}{l}\text { The policies } \\
\text { are clear, } \\
\text { unambiguou } \\
\text { s and } \\
\text { concise }\end{array}$ & $\begin{array}{l}4.004 \\
0\end{array}$ & 0.59109 & $\begin{array}{l}246.09 \\
6\end{array}$ & .000 \\
\hline $\begin{array}{l}\text { Standard } \\
\text { operating } \\
\text { procedures } \\
\text { are well } \\
\text { displayed at } \\
\text { work station }\end{array}$ & $\begin{array}{l}3.736 \\
0\end{array}$ & 0.63555 & 68.768 & .000 \\
\hline $\begin{array}{l}\text { Majority of } \\
\text { the staff } \\
\text { implement } \\
\text { the Standard } \\
\text { operating } \\
\text { procedures }\end{array}$ & $\begin{array}{l}3.496 \\
0\end{array}$ & 0.76703 & $\begin{array}{l}110.25 \\
6\end{array}$ & .000 \\
\hline $\begin{array}{l}\text { I have a } \\
\text { copy of the } \\
\text { Standard } \\
\text { treatment } \\
\text { guidelines } \\
\text { and HIV test } \\
\text { kits }\end{array}$ & $\begin{array}{l}3.369 \\
5\end{array}$ & 0.70713 & $\begin{array}{l}141.28 \\
1\end{array}$ & .000 \\
\hline $\begin{array}{l}\text { I often use } \\
\text { the } \\
\text { guidelines } \\
\text { for reference }\end{array}$ & $\begin{array}{l}3.712 \\
0\end{array}$ & 0.70359 & $\begin{array}{l}155.69 \\
6\end{array}$ & .000 \\
\hline $\begin{array}{l}\text { The } \\
\text { guidelines } \\
\text { are helpful } \\
\text { source of } \\
\text { information }\end{array}$ & $\begin{array}{l}4.044 \\
0\end{array}$ & 0.69570 & $\begin{array}{l}159.44 \\
0\end{array}$ & .000 \\
\hline
\end{tabular}

The third objective was to assess if the availability of Standard Operating Procedures (SOPs) influence reporting rates of HIV test kits in Meru County. The study established that the respondents agreed to the statement that they were aware of HIV test kits policies that are in place $(3.88 \pm 0.65)(x 2=189.6$, $\mathrm{p}<0.05)$ and the agreed that the policies were helpful at their work $(3.89 \pm 0.708) \quad(x 2=312.48, \mathrm{p}<0.05)$. The respondents

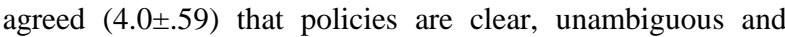
concise $(x 2=246.09, \mathrm{p}<0.05)$. Nascop as a national program have developed standards operating procedures that define steps to be followed in receiving, accounting and reporting of HIV test kits. The documents after development are usually disseminated throughout the country targeting all facilities for health care workers to refer. This agreed with the respondent that the Policy and guidelines are available and they are aware of their existence. The documents are well packaged with clear simple language that is understood by the health Care Workers. This further agreed with WHO (2020), who stated that national policies and regulations are prerequisite for promotion, support implementation of sound practices for HIV test kits management. The respondents were not sure (neither agreed nor disagreed) that Standard operating

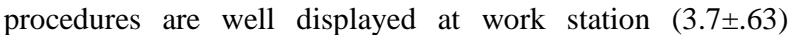
$(x 2=68.76, \mathrm{p}<0.05)$. Majority $(3.5 \pm .76)$ were not sure if the majority of the staff implemented the Standard operating procedures $(x 2=110.25, \mathrm{p}<0.05)$ and that they had a copy of the Standard treatment guidelines and HIV test kits (3.3..70). Majority of the Healthcare workers indicated that they often used the guidelines for reference (3.71 \pm .70$)$ and these

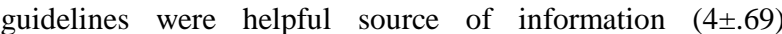
$(x 2=159.44, \mathrm{p}<0.05)$.

Table 5: Organizational factors and HIV test kits reporting rates

Organizational factors and HIV test kits reporting rates Mean Std. Chi- Asymp. Deviation Square Sig.

\begin{tabular}{|c|c|c|c|c|}
\hline $\begin{array}{l}\text { I have a } \\
\text { supervisor } \\
\text { whom I report } \\
\text { to in the } \\
\text { course of my } \\
\text { work }\end{array}$ & 3.8080 & 0.73025 & $159.376^{\mathrm{a}}$ & .000 \\
\hline $\begin{array}{l}\text { The supervisor } \\
\text { is always } \\
\text { available for } \\
\text { consultation }\end{array}$ & 3.0600 & 2.18253 & 84.89 & .000 \\
\hline $\begin{array}{l}\text { The supervisor } \\
\text { gives valuable } \\
\text { feedback }\end{array}$ & 3.8040 & 1.14316 & 122.32 & .000 \\
\hline $\begin{array}{l}\text { Supervision is } \\
\text { adequate and } \\
\text { builds capacity }\end{array}$ & 3.4680 & 1.34768 & 64.5 & .000 \\
\hline $\begin{array}{l}\text { I have attended } \\
\text { training(s) and } \\
\text { or workshop(s) }\end{array}$ & 3.4378 & 1.34597 & 80.900 & .000 \\
\hline $\begin{array}{l}\text { The training } \\
\text { was educative } \\
\text { and } \\
\text { informative }\end{array}$ & 3.4400 & 1.30430 & 50.520 & .000 \\
\hline $\begin{array}{l}\text { New staff are } \\
\text { taken through } \\
\text { an induction } \\
\text { training on as } \\
\text { part of }\end{array}$ & 3.4200 & 1.36052 & 73.00 & .000 \\
\hline
\end{tabular}




\begin{tabular}{|c|c|c|c|c|}
\hline $\begin{array}{l}\text { orientation } \\
\text { process }\end{array}$ & & & & \\
\hline $\begin{array}{l}\text { The supervisor } \\
\text { has developed } \\
\text { a hospital } \\
\text { formulary } \\
\text { which is } \\
\text { reviewed } \\
\text { periodically }\end{array}$ & 3.7800 & 1.11741 & 171.32 & .000 \\
\hline
\end{tabular}

the respondents agreed $(3.8 \pm .73)$ that they had a supervisor whom they report to in the course of their work $(x 2=159.37$, $\mathrm{p}<0.05$ ) and that their supervisor was not always available for consultation $(3.06 \pm 2.1)(x 2=84.89, \mathrm{p}<0.05)$. Sites within the county are usually manned under the leadership of the County and sub county health teams whose mandate is to make regular visits mainly on monthly basis to facilitate information flow, share feedback and also boost staffs morale. And this agreed with Asante \& Roberts (2017), who said supportive supervision can be implemented or applied at multiple levels within a public health system. Majority of the staff disagreed that the supervision was adequate and builds capacity $(3.4 \pm 1.34)(x 2=64.5, \mathrm{p}<0.05)$ and further disagreed that they

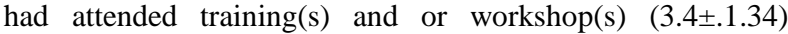
$(x 2=80.9, \mathrm{p}<0.05)$. According to Avortri et al (2019) studies have linked supportive supervision to positive outcomes such as job motivation, retention, satisfaction and better performance.

It was established that new staffs were not taken through an induction training on as part of orientation process $(3.42 \pm 1.36)(x 2=73.0, \mathrm{p}<0.05)$ and the respondents further asserted that supervisor had developed a hospital formulary which were reviewed periodically $(3.8 \pm 1.1) \quad(\mathrm{x} 2=171.32$, $\mathrm{p}<0.05)$.

\section{Table 6: Correlation Matrix}

\begin{tabular}{|c|c|c|c|c|c|c|c|}
\hline \multirow{11}{*}{ Spearman's rho } & & & Reporting Rates & avdrt & hcc & avP\&G & S-Sup \\
\hline & \multirow[t]{2}{*}{ Reporting Rates } & Rho value & 1.000 & $.693 *$ & $.896^{*}$ & $.814^{*}$ & $.407 *$ \\
\hline & & Sig. (2-tailed) & . & .025 & .054 & .015 & .053 \\
\hline & \multirow[t]{2}{*}{ avdrt } & Rho value & $.693 *$ & 1.000 & $.157 *$ & $.125^{*}$ & .649 \\
\hline & & Sig. (2-tailed) & .025 & . & .013 & .048 & $.029 *$ \\
\hline & \multirow[t]{2}{*}{ hcc } & Rho value & $.896^{*}$ & $.125^{*}$ & 1.000 & .108 & -.277 \\
\hline & & Sig. (2-tailed) & .054 & .048 & . & .089 & .069 \\
\hline & \multirow[t]{2}{*}{ avSop } & Rho value & $.814^{*}$ & .108 & $.157 *$ & 1.000 & .214 \\
\hline & & Sig. (2-tailed) & .015 & .089 & .013 & . & .079 \\
\hline & \multirow[t]{2}{*}{ S-Sup } & Rho value & $.407 *$ & .649 & .277 & .214 & 1.000 \\
\hline & & Sig. (2-tailed) & .053 & $.029 *$ & .069 & .079 & \\
\hline
\end{tabular}

*. Correlation is significant at the 0.05 level (2-tailed).

It was found that there was strong positive relationship that was significant $(\mathrm{p}<0.05)$ between reporting rates and availability of the recommended reporting tools (rho=.693, $\mathrm{p}<0.05)$ while a strong positive relationship existed between reporting rates and availability of Standard Operating Procedures(SOPs) $\quad($ rho $=-.814, \quad \mathrm{p}<0.05) \quad$ and $\mathrm{a}$ strong relationship between the reporting rates and human capacity $(\mathrm{rho}=.896, \mathrm{p}=054)$ and organizational factors(rho=.407, $\mathrm{p}=.053$ ) and thus presence of enough staff, availability of Reporting tools, SOPs and supportive supervision all affects reporting rates for HIV test kits.

Table 7: Regression model Summary

\begin{tabular}{lllll} 
Model & $\mathrm{R}$ & R Square & Adjusted R Square & Std. Error of the Estimate \\
\hline 1 & $.814^{\mathrm{a}}$ & .663 & .709 & 3.63258 \\
a. Predictors: (Constant), S-Sup, avdrt, avP\&G, hcc & &
\end{tabular}

The coefficient of determination obtained from the model was .663 and this indicated that the regression model explained only $66.3 \%$ of the factors that explained/affected reporting rates on consumption data of HIV test kits in the county.
Thus, other factors that were not captured in the model explained $32.7 \%$ and this explained the $f$ statistics which indicates that the model was significant $\left(f_{\text {cal. }} p<0.05\right)$.

Table 8: ANOVA

\begin{tabular}{lllllll}
\hline Model & & Sum of Squares & df & Mean Square & F & Sig. \\
\hline 1 & Regression & 137.643 & 4 & 34.411 & 10.185 & .046 \\
& Residual & 45532.581 & 245 & 185.847 & & \\
& Total & 45670.224 & 249 & & &
\end{tabular}
a. Dependent Variable: Reporting Rates
b. Predictors: (Constant), S-Sup, avdrt, avSops, hcc 
Table 9: Coefficients

\begin{tabular}{|c|c|c|c|c|c|}
\hline \multirow[b]{2}{*}{ Model } & \multicolumn{2}{|c|}{ Unstandardized Coefficients } & \multirow[t]{2}{*}{ Standardized Coefficients } & \multirow{3}{*}{$\begin{array}{l}\mathrm{t} \\
5.010\end{array}$} & \multirow{3}{*}{$\begin{array}{l}\text { Sig. } \\
.000\end{array}$} \\
\hline & $\mathrm{B}$ & Std. Error & & & \\
\hline $1 \quad$ (Constant) & 82.877 & 16.544 & & & \\
\hline avdrts & .087 & .174 & .032 & 4.498 & .019 \\
\hline hcc & .047 & .241 & .013 & 3.197 & .044 \\
\hline avSops & .017 & .500 & .002 & .134 & .073 \\
\hline S-Sup & .121 & .184 & .042 & 4.657 & .012 \\
\hline
\end{tabular}

a. Dependent Variable: Reporting_Rates

Holding other factors constant, the reporting rates using the $\mathrm{MOH} 643$ reporting rates was 83. A unit change in human capacity led to .047 unit increases in the reporting rates compared to a .087 increase for a unit change in availability of reporting tools (MOH 643). A unit change in availability of SOPs in the health facilities led to .017 increases in reporting rates while a unit change in support supervision led to a .121 increase in reporting rates.

\section{CONCLUSIONS}

The study established that majority approximately $43 \%$ had worked at their current station for between 6-10 years while a third had experience of between 1-5 years. It was found that there was strong positive relationship that was significant $(\mathrm{p}<0.05)$ between reporting rates and availability of the reporting tools $(\mathrm{rho}=.693, \mathrm{p}<0.05)$ while a strong positive relationship existed between reporting rates and availability of Policy and guidelines $(\mathrm{rho}=.814, \mathrm{p}<0.05)$ and a strong relationship between the reporting rates and human capacity $(\mathrm{rho}=.896, \mathrm{p}=054)$ and support supervision $(\mathrm{rho}=-.407$, $\mathrm{p}=.053$ ) and thus presence of enough staff, availability of Policy and guidelines, supportive supervision all affects use and utilization of reporting tools (MOH 643) in usage of HIV testing kits.

The coefficient of determination obtained from the model was .663 and this indicated that the regression model explained only $66.3 \%$ of the factors that affected/explained reporting rates on consumption data of HIV test kits in the county. In the regression model holding other factors constant, the reporting rates using the $\mathrm{MOH} 643$ was 83 . A unit change in human capacity led to .047 unit increases in reporting rates compared to a .087 increase for a unit change in availability of reporting tools (MOH 643). A unit change in availability of Standard Operating Procedure in the health facilities led to .017 increases in reporting rates while a unit change in support supervision led to a .121 increase in reporting rates

Slightly more than half of the Healthcare workers were regularly trained in the recommended data reporting tools approximately $40.4 \%$ cited that recommended data reporting tools (MOH 643) was adequate in capturing the consumption data of the HIV test kits. Most of the Healthcare workers were trained once and further query indicated that this once trainings affected the reporting rates due to inadequate competence. These trainings were not quite adequate in the capture of consumption data on HIV test kits. Further, these trainings were not useful.

The Healthcare workers were aware of HIV test kits policies that are in place and the further the policies were helpful at their work. The various policies on reporting rates were clear, unambiguous and concise. The respondents were not sure that Standard operating procedures are well displayed at work station and this might have affected the reporting rates. Majority were not sure if the majority of the staff implemented the Standard operating procedures and that they had a copy of the Standard treatment guidelines and HIV test kits. Most healthcare workers in the study had a supervisor whom they report to in the course of their work though supervisors were not always available for consultation but often provided valuable feedback. Most staff disagreed that the supervision was adequate and builds capacity and further they had not attended training(s) and or workshop(s). It was established that new staffs were taken through induction training on as part of orientation process.

\section{RECOMMENDATIONS}

To improve of reporting rates for HIV test kits in Meru County, there is a need to ensure recommended reporting tools for HIV test kits are updated to accommodate the new upcoming kits. As per the study ,85(34.0\%) of health care workers indicated that recommended reporting tools for HIV test kits should be updated to accommodate new test kits. This should be a collaborative effort between the County leadership and the National program mandated to review, print and distribute reporting tools for HIV test kits to facilities across the county

Support supervision should be intensified by the county and sub county leadership. Respondents indicated that they are aware of their supervisors but rarely are they available for consultation. Site visits by the supervisors to facilities can play a key role in ensuring health care workers are mentored and supported on the need to management and report HIV test kits. Collaborative effort between the county and other key actors in health is very key for resource mobilization to facilitate the County/sub county team to make regular visits to the facilities. Clear work plan should be developed to guide site visits on monthly /quarterly basis.

\section{COMPETING INTEREST}

The authors declare that they have no competing interests

\section{AUTHORS CONTRIBUTIONS}

Paul Gathii conceptualized the study. All authors contributed to study design and data analysis. All the authors reviewed and approved the final version of the publication manuscript.

\section{REFERENCES}

[1] Agarwal [2020] Evaluation of Standard Operating procedures for HIV \& Syphilis Screening of pregnant women at VHSN Sites, Bangladesh.

[2] Asante A. \& Roberts G. (2017). Strengthening supportive supervision at the district health level in the Pacific. Human Resources for Health Knowledge Hub, University of New South Wales.

[3] Bailey C, et al, A systematic review of supportive supervision as a strategy to improve primary healthcare 
services in SubSaharan Africa, Int J Gynecol Obstet (2015), http://dx.doi.org/10.1016/j.ijgo.2015.10.004

[4] Burma, Z. (2014). Human Resource Management and Its Importance for Today's Healthcare facilites.International Journal of Education and Social Science, Vol.1 No.2, 110.

[5] Chapagain, D. (2009). Japanese Style Management. Retrieved from http://www.dineshchapagain.com.np/admin/files/Japanes e\%20Style\%20Management.pdf

[6] Chuang, S.-F. (2013). Evaluating training and development practices in Taiwan: challenges and opportunities. Human Resource Development International, 16(2), 230-237. http://doi.org/10.1080/13678868.2012.7561547, 1

[7] Dieleman, M., Gerretsen, B., \& van der Wilt, G. J. (2019). Human resource management interventions to improve health workers' performance in low and middle income countries: a realist review. Health Research Policy and Systems, 7(1). http://doi.org/10.1186/14784505-7-7

[8] Djibuti, M, (2009). The role of supportive supervision on immunization program outcome - a randomized field trial from Georgia. BMC International Health and Human Rights 9 (Suppl 1)

[9] Gichangi A, Wambua J, Mutwiwa S, Njogu R, Bazant E, Wamicwe J, et al. Impact of HIV self-test distribution to male partners of ANC clients: results of a randomized controlled trial in Kenya. J Acquir Immune Defic Syndr. 2018 Aug 16. doi: 10.1097/QAI.0000000000001838

[10] Global AIDS Update 2018: Miles to go: Closing gaps, breaking barriers, righting injustices. Geneva: Joint United Nations Programme on HIV/AIDS; 2018

[11] Hutchings, K., Zhu, C. J., Cooper, B. K., Zhang, Y., \& Shao, S. (2009). Perceptions of the effectiveness of training and development of "grey-collar" workers in the People's Republic of China.Human Resource Development International, 12(3), 279-296. http://doi.org/10.1080/13678860902982033

[12] Kwon, K., Bae, J., \& Lawler, J. J. (2010). High Commitment HR Practices and Top Performers: Impacts on Organizational Commitment. Management
International Review, 50(1), 57-80 http://doi.org/10.1007/s11575-009-0023-6

[13] Management Sciences for Health (MSH) (2018). Managing Data with DHIS2: Improving Health Commodities Reporting and Decision Making in Kenya. https://www.msh.org/news-events/stories/managing-datawith-dhis2-improving-healthcommodities-reporting-anddecision

[14] Martin A. and Simmons E. (2017). Better Decision Making with Proper Business Intelligence. Quality information is key to making quick, rational business decisions

[15] McClean, E., \& Collins, C. J. (2011). High-commitment HR practices, employee effort, and firm performance: Investigating the effects of HR practices across employee groups within professional services firms. Human Resource Management, 50(3), 341-363. http://doi.org/10.1002/hrm.20429

[16] Mounica B. (2016). Efficient Reporting Tool for Business Intelligence with Increasing Volume of Data. , International Journal of Computer Science and Mobile Computing, Vol.5 Issue.1, January- 2016, pg. 86-90

[17] Sibanda E, Neuman M, Tumushime M, Hatzold K, Watadzaushe C, Mutseta M, et al. Linkage to care after HIV self-testing in Zimbabwe: a cluster-randomised trial Conference on Opportunistic Infections and Retroviruses, Boston, USA; 3-6 March 2018 (http://www.croiwebcasts.org/console/player/37325?med iaType $=$ slideVideo $\&$,

[18] Stover J, Bollinger L, Izazola J, Loures L, DeLay P, Ghys P. (2020) What is required to end the AIDS epidemic as a public health threat by 2030 ? The cost and impact of the fast-track approach. PLoS ONE.11(6):e0158253.

[19] WHO (2014). HIV Rapid Testing: Training Package, Centers for Disease Control and Prevention (CDC), World Health Organization (WHO), Office of the United States Global AIDS Coordinator, and the US Department of Health and Human Services (DHHS).

[20] World Health Organization (2016). Guidelines on HIV self-testing and partner notification: a supplement to the consolidated guidelines on HIV testing services. Geneva: 